\title{
Benadeel konvensionele grondbewerkingspraktyke die biodiversiteit in wingerdgronde?
}

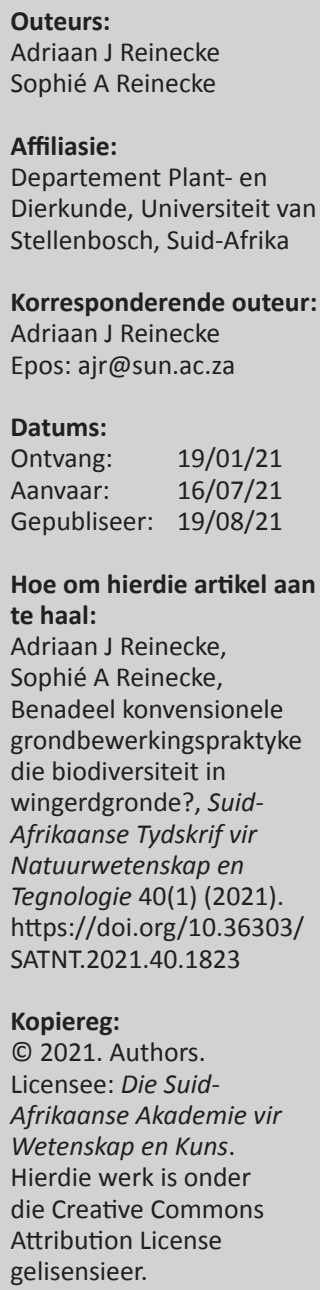

Die invloed van konvensionele en organiese grondbewerkingspraktyke op die getalle, diversiteit en aktiwiteit van grondlewende mesofauna in wingerdgrond is in hierdie kwantatiewe veldstudie gedurende verskeie seisoene ondersoek. Grondmonsters is oor verskeie seisoene in organies en konvensioneel-bewerkte persele sowel as in 'n kontroleperseel geneem. Organismes is ge-ekstraheer om die mesofauna (meestal Collembola en Acari) te tel en te identifiseer. Die voedingsaktiwiteit van die mesofauna in die grond is ook met die aaslamina-metode bepaal en strooiselsakkies is begrawe om organiese afbraak deur organismes oor tyd te meet.

Geen statistiesbeduidende verskille in getalledigtheid, diversiteit en aktiwiteit van die mesofauna is tussen die organies- en die konvensioneel-bewerkte grond gevind nie. Ons gestelde hipotese kon nie aanvaar word dat die konvensionele praktyk, soos hier be-oefen, nadeliger was as die organiese bewerking nie. Die aktiwiteit van die mesofauna was beduidend hoër in die twee bewerkte persele as in die onbewerkte, natuurlike kontroleperseel. Die afleiding is dat die toestande wat in die twee bewerkte persele geskep is, gunstig was vir die mesofauna.

Trefwoorde: konvensionele grondbewerking, biodiversiteit, mesofauna; wingerdgrond

Do conventional soil management practices harm biodiversity in vineyard soils?: The influence of organic and conventional soil management practises on the density, diversity and activity of the soil dwelling mesofauna in vineyard soil were investigated over several seasons in this quantitative field study. Soil samples were taken over several seasons in organically and conventionally managed plots as well as in a natural control plot and organisms were extracted to count and identify the soil mesofauna (mostly Collembola and Acari). The feeding activity of the mesofauna in the soil was measured with the bait lamina method and buried litter bags to measure the decomposition of organic material over time.

No statistically significant differences in numbers, diversity and activity of the mesofauna were found between the organically and conventionally managed plots. Therefore our stated hypothesis that the conventional practice, as employed here, would be detrimental compared to the organic treatment, could not be accepted. The activity of the mesofauna was significantly higher in the two managed plots than in the natural, untreated control plot from which we deduce that conditions in the two managed plots were favourable for the mesofauna.

Keywords: conventional soil management, biodiversity, mesofauna, vineyard soil

\section{Inleiding}

Die vrugte- en wynbedryf beskou volhoubaarheid as 'n hoë prioriteit (Flores 2018) en streef daarna om wingerdgrond in ' $n$ beter toestand vir die volgende generasies na te laat. Moderne, intensiewe landboupraktyke word egter as ernstige bedreiging vir biodiversiteit beskou (Hole et al., 2005). Die bedryf maak onder andere van 'n verskeidenheid plaag- en ander middels gebruik om gewasse te bespuit en oeste te beskerm teen insekte, swamme en onkruidgewasse. Dit het daartoe gelei dat "volhoubare" praktyke soos organiese boerdery en bewaringsboerdery as moontlike oplossings gesien word om verlies aan biodiversiteit teen te werk sonder om opbrengs in te boet. Mayer et al. (2015) het bevind dat, alhoewel organiese praktyke die mikrobiese aktiwiteit in grond verhoog in vergelyking met konvensionele praktyke, dit nie opbrengs verbeter het nie. Hoewel organiese praktyke sonder twyfel sekere voordele inhou (Reinecke et al., 2002, 2008; Gaigher \& Samways 2010; Tuck et al., 2014; Henneron et al., 2015) is daar ook meningsverskille oor ekonomiese volhoubaarheid van sekere praktyke (Giller et al., 
2009) en word dit uitgewys dat nie alle taksa van organismes deur organiese bewerkingspraktyke bevoordeel word nie. Ook is die meeste studies beperk tot lande in die noordelike halfrond met anderssoortige omstandighede as in SuidAfrika.

Sommige navorsers meen dat die versigtige bestuur van konvensionele of geïntegreerde bewerkingspraktyke, wat nie van "aggressiewe" plaagmiddels gebruik maak nie, steeds 'n opsie is (Gaigher \& Samways 2010; Gomeiro et al., 2011), veral omdat kwantitatiewe gegewens oor werklike langtermynvoordele nog ontbreek.

Grond huisves 'n baie groot verskeidenheid organismes wat 'n bydrae lewer tot baie komplekse prosesse (Briones 2014). Henneron et al. (2015) het na 'n studie wat oor veertien jaar gestrek het, bevind dat die bevordering van grondlewende gemeenskappe die kwaliteit van grond kan verbeter en volhoubaarheid kan bevorder. Dit is egter moeilik om die organismes se onderskeie ekologiese rolle in biogeochemiese kringlope te kwantifiseer. Uit ' $n$ ekologiese oogpunt is ' $n$ beter begrip van hierdie rolle van belang vir volhoubare bewerking van landbougronde, veral omdat sekere chemiese plaagbeheermiddels nadelige gevolge vir grondgemeenskappe kan inhou (Reinecke \& Reinecke 2007, 2018).

Hoewel daar robuuste getuienes is dat organiese grondbewerkingspraktyke in sommige wêrelddele voordelig is vir grondbiodiversiteit, is die invloed van verskillende bewerkinspraktyke op die mesofauna in wingerdgronde nog nie indringend in Suid-Afrika ondersoek nie. Die mesofauna speel volgens Brussaard (1998) 'n belangrike rol in die verwerking en inkorporering van die strooiselbolaag in die grond, hoewel hulle nie die enigste rolspelers is nie. Hulle beïnvloed die koers waarteen ontbinding en humifikasie deur mikro-organismes plaasvind en voed ook op die bakterieë en swamme in die organiese substraat.

Die doel van hierdie veldstudie was om die uitwerking van organiese en konvensionele bewerkingspraktyke op die getalle en aktiwiteit van grondmesofauna oor verskeie seisoene in wingerdgrond te vergelyk deur van kwanitatiewe metodes gebruik te maak. Die oogmerk is om die hipotese dat konvensionele grondbewerkingpraktyke nadeliger is as organiese praktyke, vir'n spesifieke geval, te ondersoek.

\section{Materiaal en metodes \\ Studiegebied en grondparameters}

Die veldwerk is op ' $n$ wynplaas uitgevoer waar 375 hektaar van 'n moontlike 402 hektaar vir wynbou aangewend word. Die plaas is in Simondium $\left(33^{\circ}, 5^{\prime}\right.$ 'Suid; $18^{\circ}, 56^{\prime}$ Oos $)$ in die Paarl vallei, Weskaap, Suid-Afrika, geleë. Op die plaas word beide konvensionele en organiese grondbewerkingspraktyke in die wingerde reeds vir meer as drie jaar toegepas.
Een ondersoekperseel is in elk van die konvensionele en organies bestuurde wingerde uitgekies. Die grondparameters ( $\mathrm{pH}$, waterhouvermoë, organiese materiaal inhoud, persentasie sand klei en slik) is met die aanvang van die veldopnames gemeet. Die grond van beide die konvensionele en die organiese persele het 'n kommersiële bemestingstof met die handelsnaam Neutrog® ontvang wat hoendermis bevat. Die grond tussen die wingerdrye is meganies gebreek en met strooi bedek. 'n Dekgewas is voor die aanvang van die studie tussen die rye gesaai en 'n kommersiële produk met die naam Seagrow ${ }^{\circledR}$, wat vismeel bevat, is as grondverbeteraar/kondisioneerder gebruik. Hierde behandelinge is op beide die organiese en konvensionele persele toegepas.

Die enigste verskil in die behandeling van die twee persele was die plaagmiddels (Tabel 1) wat op die onderskeie persele gebruik is. Geen inligting was beskikbaar oor die dosis of frekwensie van bespuiting nie. Bespuitings het na gelang van behoefte en omstandighede deur die loop van die seisoen plaasgevind. Dit was nie die doel om grondbiologiese aktiwiteit oor tyd met omgewingsfaktore, wat soortgelyk was vir alle persele, te korreleer nie. As kontrole, is 'n naasliggende, voorheen onbewerkte gebied met natuurlike plantegroei reg langs die wingerd, gekies met soortgelyke grondeienskappe soos $\mathrm{pH}$ waterhouvermoë (WHC), organiese materiaal inhoud en grondtekstuur. Die grond se $\mathrm{pH}$ is met ' $\mathrm{n}$ Crison micropH 2001 meter gemeet. Waterhouvermoë (WHC) is met 'n polistireenbord met ses uitgesnyde afdelings bepaal. Gaas is onder in die bord gesit. 'n Grondmonster is op filtreerpapier geplaas en bo-op die gaas geplaas waarna die hele bord in $n$ watergevulde skinkbord gesit is sodat die grond die water kan absorbeer. Na verloop van drie ure is die plaat met waterversadigde grondmonsters vir twee ure op 'n klam sandbed geplaas om te dreineer. Daarna is die grondmonsters geweeg en vir 48 uur by $60^{\circ} \mathrm{C}$ gedroog en weer geweeg om die waterinhoud te bepaal.

TABEL 1: Chemiese middels wat op die persele gebruik is vir swambeheer in die wingerd.

\begin{tabular}{c|c}
\hline Konvensioneel & Organies \\
\hline Koperhidroksied & Koperhidroksied \\
Mancozeb & Swawel \\
Penkonasool & \\
Swawel & \\
Trifloksistrobien & \\
\hline
\end{tabular}

Die organiese materiaal inhoud van die grondmonsters is met ' $n$ standaardmetode in 'n Gallenkamp-verbrandingsoond by $500^{\circ} \mathrm{C}$ bepaal deur gewig voor en na verbranding te vergelyk.

Die grondtekstuur van die verskillende persele is goedgunstiglik deur die Departement Grondkunde by Stellenbosch Universiteit bepaal deur van siwwe met verskillende maasgrotes gebruik te maak om die persentasies sand, slik en klei te bepaal. 


\section{Kwantitatiewe monsterneming en ekstraksie van mesofauna}

Voor die aanvang van die kwantatiewe ondersoek van die aktiwiteit van die mesofauna is eenmalige kwalitatiewe monsters op elk van die drie persele geneem om 'n beeld te verkry van die aanwesige mesofauna. Daarna is sewe monsters per perseel elke maand in elk van die drie persele geneem vir' $n$ periode van veertien opeenvolgende maande om te verseker dat alle seisoene gedek word. Dit is gedoen deur 'n vlekvrye staalsilinder ( $\varnothing 5 \mathrm{~cm}, 7 \mathrm{~cm}$ hoog) te gebruik wat aan beide kante oop is. Een kant is skerp gemaak om dit makliker met ' $n$ houthamer in die grond te kan inkap. Nadat die silinders uit die grond verwyder is, is dit aan beide ente met deksels toegemaak om vogverlies te bekamp. Volgens Macfadyen (1961) vergemaklik die vog die ekstraksieproses. In die laboratorium is die deksels met gaas (0.5 mm maasgrootte) vervang en is die silinders vir sewe dae in 'n Tullgren-ekstraktor geplaas om die mesofauna van die grond te skei (Van Straalen \& Rijninks 1982).

Die geëkstraheerde organismes is onder 'n disseksiemikroskoop ge-identifiseer en in hoofgroepe verdeel met behulp van Eisenbeis en Wichard (1987), Picker et al, (2002) en persoonlike notas wat prof. C.A.M.van Gestel (Vrjie Universiteit in Nederland) beskikbaar gestel het.

\section{Bepaling van biologiese aktiwiteit in die grond}

Drie metodes is in hierdie studie gebruik om biologiese aktiwiteit te meet naamlik die aaslamina ("Bait lamina"), strooiselsakkies ("Litterbags") en $\mathrm{CO}_{2}$-vloed.

Die aaslamina-toets wat deur Von Törne (1990) ontwikkel is en deur verskeie navorsers gebruik is (Larink 1994; Kratz 1998;Reinecke et al., 2002; 2008), meet die voedingsaktiwiteit van grondorganismes. Dit is ook bruikbaar om kleinskaalse verspreiding van biologiese aktiwiteit te meet (Helling et al., 1998; Paulus et al., 1999). Die toets behels verskeie stelle van geperforeerde klein plastiekstroke (Figuur 1). Die openinge word met die aas gevul en die strokies word in die grond geplant om hulle aan die grondorganismes bloot te stel.

Die plastiekstrokies wat in hierdie studie gebruik is, het 'n lengte van $140 \mathrm{~mm}$, 'n breedte van $5 \mathrm{~mm}$ en 'n dikte van 1.5 $\mathrm{mm}$ (Figuur 1). Elke strokie het 16 openinge van $2 \mathrm{~mm}$ wat skuinsweg na die buite-oppervlak vergroot tot $4 \mathrm{~mm}$, Die opening is met ' $n$ aas gevul bestaande uit ' $n$ klam mengsel van sellulose poeier, brandnetelblaar poeier en agar-agar in die verhouding 6.5: 2.5: 1 . Die mengsel is met ' $n$ mes in die opening gesmeer en die strokies is vir 24 uur in ' $n$ oond by $40^{\circ} \mathrm{C}$ gedroog (Helling et al. 1998) (Figuur 1). 'n Stel van 16 aasbevattende strokies is as toetsstel gebruik,

Vertikale gleuwe is minstens $20 \mathrm{~cm}$ van mekaar af met 'n mes in die grond gemaak en een stel strokies is in die grond van elk van die drie persele gesteek. Die laminas is na tien dae versigtig uitgehaal en grond is met ' $n$ klam lap afgevee.

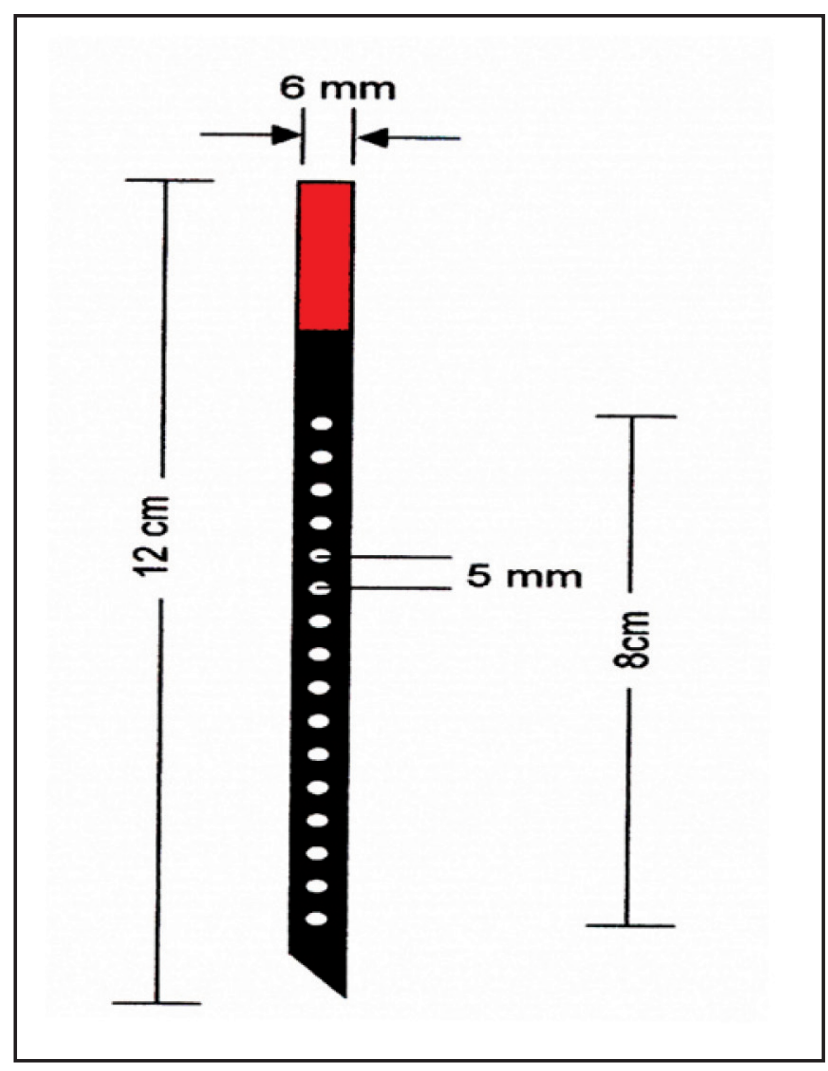

FIGUUR 1: Afmetings van die aaslamima strokie wat gebruik is om voedingsaktiwiteit te bepaal.

Die lamina is op 'n ligtafel geplaas om die getal leë openinge te tel.

Die strooiselsakkie-metode is deur Bocock \& Gilbert (1957) beskryf. Dit behels die insluiting van 'n vasgestelde hoeveelheid gedroogde organiese materiaal wat in gaassakkies geplaas en in die grond begrawe word om deur grondorganismes afgebreek te word.

In die studie, is sakkies uit nie-afbreekbare nylon gaas met $1 \mathrm{~mm}$ maasgrootte gemaak en met afmetings van $10 \mathrm{~cm}$ by 15 cm (Reardon \& Forbes 200;, Knacker et al., 2003). Die maasgrootte sluit die invloed van groter grondorganismes soos erdwurms en insekte uit sodat die rol van die mesofauna gemeet kan word. Elke genommerde strooiselsakkie is met $10 \mathrm{~g}$ grasstrooi gevul wat vooraf vir 48 uur by $60^{\circ} \mathrm{C}$ gedroog is (Mateo \& Romero 1996). Tien gevulde sakkies is geweeg en in elkeen van die drie persele op afstande van minstens $50 \mathrm{~cm}$ van mekaar en teen 'n diepte van $5 \mathrm{~cm}$ begrawe. Die posisies is met penne gemerk. Die sakkies is van Oktober tot Januarie vir 'n periode van drie maande in die grond gelaat voordat dit herwin en individueel gewas is om alle grond aan die buitekant te verwyder. Daarna is hulle vir 24 uur by $80^{\circ} \mathrm{C}$ gedroog en opnuut geweeg en die gewigsverlies is as ' $n$ persentasie van die oorspronklike gewig uitgedruk.

Die $\mathrm{CO}_{2}$-vloed is op 'n diepte van $2 \mathrm{~cm}$ op al drie persele gemeet as 'n verdere moontlike maatstaf van biologiese aktiwiteit. $\mathrm{CO}_{2}$ word aan die atmosfeer vrygestel as gevolg 
van respirasie van mikro-organismes en ander organismes wat betrokke is by heterotrofiese ontbinding van organiese materiaal en plantstrooisel. Alhoewel dit moeilik is om te bepaal wat die onderskeie rolspelers se relatiewe bydrae tot die gemete $\mathrm{CO}_{2}$-vloed is, kan dit ' $\mathrm{n}$ aanduiding bied van hoe die totale aktiwiteit in die verskillende persele verskil. Dit is eenmalig aan die begin van die ondersoek gemeet. ie grond is vir 24 uur geïnkubeer by onderskeidelik $20^{\circ} \mathrm{C}$ en $35^{\circ} \mathrm{C}$ om winter- en somertemperature te simuleer. Die $\mathrm{CO}_{2}$-vloed is met 'n Licor LI-6400 PPS draagbare fotosintese stelsel en 6400-09 grond $\mathrm{CO}_{2}$-flukskamer gemeet deur tien milliliter gedistilleerde water by $50 \mathrm{~g}$ luggedroogde grond te voeg. Die grond is vir' $n$ bykomende uur in 'n groeikamer by die bovermelde temperature geïnkubeer en die $\mathrm{CO}_{2}$ vloed is dadelik gemeet (Mills \& Fey 2004).

\section{Statistiese metodes}

Alle gegewens is met MicroSoft Excel XP 2000, Jandel Scientific SigmaStat ${ }^{\circledR} 2.0$ verwerk. Die verskille in die voedingsaktiwiteite wat tussen die konvensionele, organiese en kontrolepersele met die aaslaminas verkry is, is met die Mann-Whitney $U$-test (Helling et al. 1998) ontleed. In grafiese voorstellings in die figure dui vertikale asse 0.95 sekerheisinterval aan. Vir elk van die twee bewerkte persele (organies en konvensioneel) en die kontroleperseel is betekenisvolheid van verskille in getalle organismes met die Mann-Whitney toets bepaal. Die biodiversiteit van die drie persele is met mekaar vergelyk deur van die $\Delta \mathrm{V}$ indeks van biodiversiteit (Cancela da Fonseca en Sarkar 1996) gebruik te maak vir die verskillende taksa wat wel onderskei kon word. Die belangrikste eienskappe van die indeks is:

$$
\Delta \mathrm{V}=\left[\mathrm{V}(\mathrm{x})+\mathrm{V}(\mathrm{S})+\mathrm{V}(\mathrm{n})+\mathrm{V}\left(\mathrm{H}^{\prime} \mathrm{x}\right)+\mathrm{V}\left(\mathrm{H}^{\prime} \mathrm{y}\right)\right] / 5
$$

waar $\mathrm{x}$ die volopheid van die taksonomiese groep, $\mathrm{S}$ die getal taksonomiese groepe, $\mathrm{n}$ die getal monsters waarin die groep voorgekom het, $\mathrm{H}^{\prime} \mathrm{x}$ die indeks van taksonomiese diversiteit volgens die Shannon-Weiner diversiteitsindeks en $\mathrm{H}^{\prime} \mathrm{y}$ die ruimtelike diversiteitsindeks is, en

$$
\mathrm{Vm}=(\mathrm{Cm}-\mathrm{Om}) /(\mathrm{Cm}+\mathrm{Om})
$$

waar $\mathrm{Cm}$ die waarde van die parameter $\mathrm{m}$ in die konvensionele perseel en $\mathrm{Om}$ die waarde van die parameter $\mathrm{m}$ in die organiese perseel is. Indien $\mathrm{Cm}=\mathrm{Om}$, is daar geen waarneembare verskil tussen die twee persele nie. Indien $\mathrm{Cm}<\mathrm{Om}$ is die biodiversiteit laer in die konvensionele perseel as in die organiese. Indien $\mathrm{Cm}>\mathrm{Om}$ het die organiese perseel ' $n$ hoër diversiteit. Die indeks wissel dus tussen -1 en +1 (Cortet et al., 2002; Burrows \& Edwards 2002) en is volgens Cancela da Folseca \& Sarkar (1996) 'n nuttige hulpmiddel om die intensiteit en uitwerking van menslike ingrype op biologiese gemeenskappe en ekologiese stelsels te evalueer.

Die statistiese verskille in die voedingsaktiwiteite vir die aaslaminastrokies tussen die verskillende persele is bepaal deur van die Mann- Whitney Utest gebruik te maak (Helling et al., 1998).
ANOVAs is gebruik om die verskille in spesierykheid tussen die verskillende diergroepe onder verskillende behandelings te bepaal.

\section{Resultate \\ Grondeienskappe}

Die fisiese eienskappe van die grond van die verskillende persele (Tabel 2) het in 'n redelike mate ooreen gestem hoewel die pH 7.9 was in die organies behandelde perseel, 7.1 in die konvensioneel behandelde perseel en 6 in die kontroleperseel. Die organiese materiaalinhoud van die konvensionele perseel was ook heelwat laer as die van die ander persele.

TABEL 2: Fisiese grondeienskappe van die drie ondersoekpersele. (WHC = waterhouvermoë; grondtekstuur en organiese inhoud uitgedruk as \%

\begin{tabular}{l|c|c|c|c|c|c|c}
\hline & pH & WHC & $\begin{array}{c}\text { Org. } \\
\text { inhoud }\end{array}$ & Sand & Slik & Klei & $\begin{array}{c}\text { Deeltjies } \\
>\mathbf{2 ~} \mathbf{~ m m}\end{array}$ \\
\hline Konvensioneel & 7.1 & 30 & 3.8 & 71 & 12 & 13 & 50 \\
Organies & 7.9 & 40 & 8 & 62 & 18 & 12 & 58 \\
Kontrole & 6 & 45 & 10.6 & 56 & 20 & 13 & 57 \\
\hline
\end{tabular}

\section{Grondorganismes}

Verteenwoordigers van drie families van die Collembola (springsterte) kon uit die ge-ekstraheerde grondmonsters geïdentifiseer word, naamlik die Poduromorpha, Entomobryomorpha en Symphypleona. 'n Groot aantal myte (Acari) is onderskei wat meestal uit Oribatei bestaan het. ' $n$ Klein aantal Enchytraeidae, enkele honderdpote en miere is ook onderskei maar geen fynere taksonomiese indeling is gemaak nie weens 'n gebrek aan beskikbare kundigheid. Enkele eksemplare van twee erdwurmspesies van die familie Lumbricidae naamlik Apporectodea caliginosa en Eisenia rosea het ook voorgekom.

Die getalle van die Poduromorpha (Collembola) was slegs gedurende die lente in die organiese perseel statisties beduidend ( $p<0.05)$ hoër as die ander Collembola families. Indien die getalle vir die verskillende seisoene (die opnameperiode) saamgevoeg word vir die verskillende behandelings, was die getalle van die Poduromorpha betekenisvol hoër in die organiese perseel as in beide die konvensionele en kontrolepersele $(p=0.000985)$ As al die Collembola se getalle egter vir alle persele en behandelings per seisoen saamgevoeg word, was daar geen betekenisvolle verskille $(p<0.05)$ tussen die verskillende seisoene nie.

Word al die Collembola oor die hele opnameperiode vir elke perseel saamgevoeg, was die organies-bewerkte perseel se getalle in die lente betekenisvol hoër as in die kontrole en konvensionele perseel en ook beduidend hoër gedurende die herfs ( $p=0.046584$ ), maar nie beduidend hoër as die getalle wat gedurende die winter en somer verkry is nie (Figuur 2).

Daar was geen betekenisvolle verskille $(\mathrm{p}=0.215256)$ wat die totale getalle van die myte betref in die organiese perseel tussen die verskillende seisoene nie. Die perseel het 
egter in die lente getalle gehad wat betekenisvol ( $p=$ 0.021849 ) hoër was as die getalle in die konvensioneel bewerkte perseel maar nie die van die kontroleperseel nie. Tydens die someropname het die kontroleperseel beduidend hoër ( $p=0.021849)$, getalle as die konvensionele perseel gehad, maar nie in vergelyking met die organiese perseel nie. Gedurende die herfs was die getalle van die myte in die kontrole en konvensionele persele betekenisvol hoër ( $\mathrm{p}=0.003605)$ as in die winter en lente (Figuur 3$)$.
Indien die getalle van alle versamelde mesofauna per perseel saamgevoeg word (Figuur 4) was daar geen betekenisvolle verskil $(p=0.215256)$ tussen die verskillende seisoene nie en was daar nie enige betekenisvolle veranderinge $(\mathrm{p}<0.05)$ in getalle tussen die eerste en laaste opnames vir enige van die persele nie.

Volgens die Shannon-Weiner indeks was die getalle van die mesofauna gedurende die lente en somer hoër in die

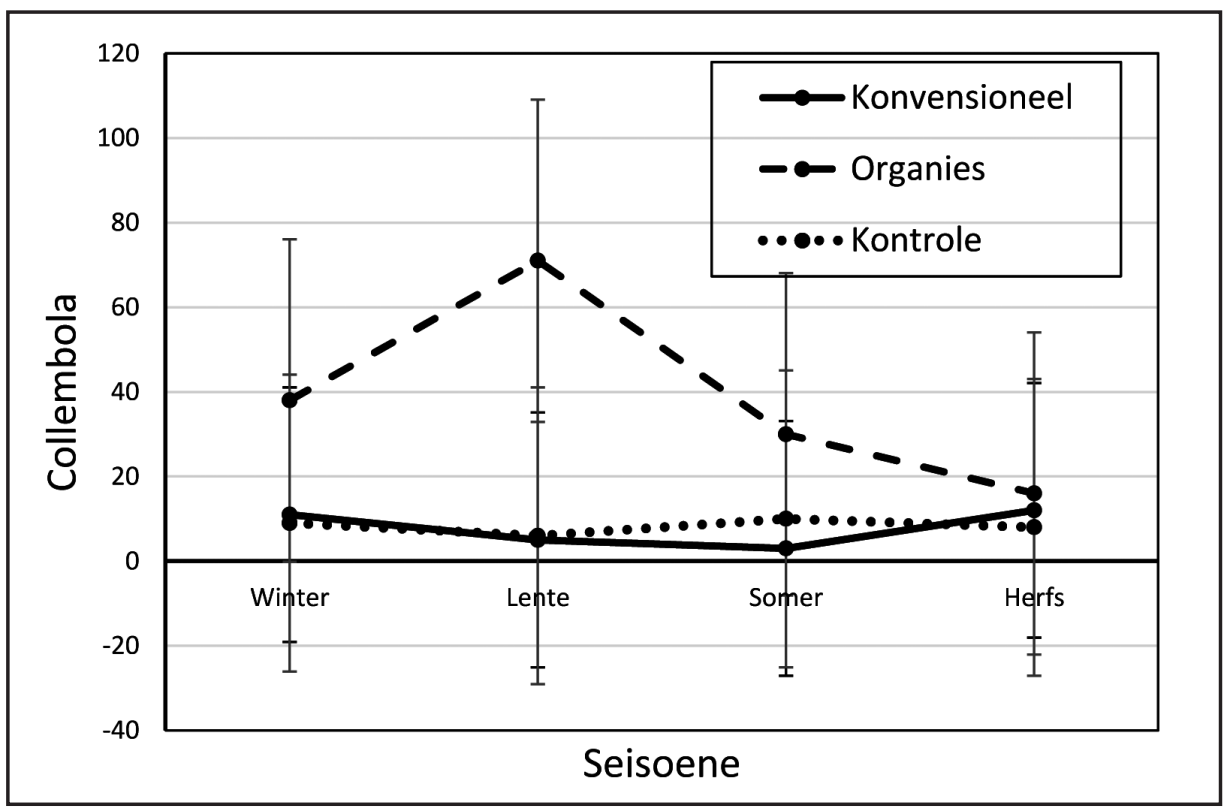

FIGUUR 2: Saamgevoegde getalledigtheid van al drie groepe van die Collembola in verskillende seisoene in die organiese, konvensionele en kontrolepersele. [behandeling*seisoen; LS Gemiddeld; Effek: $F(6.259)=2.1672, p=$ 0.4658. Vertikale kolomme - betroubaarheidsvlak 0.95]

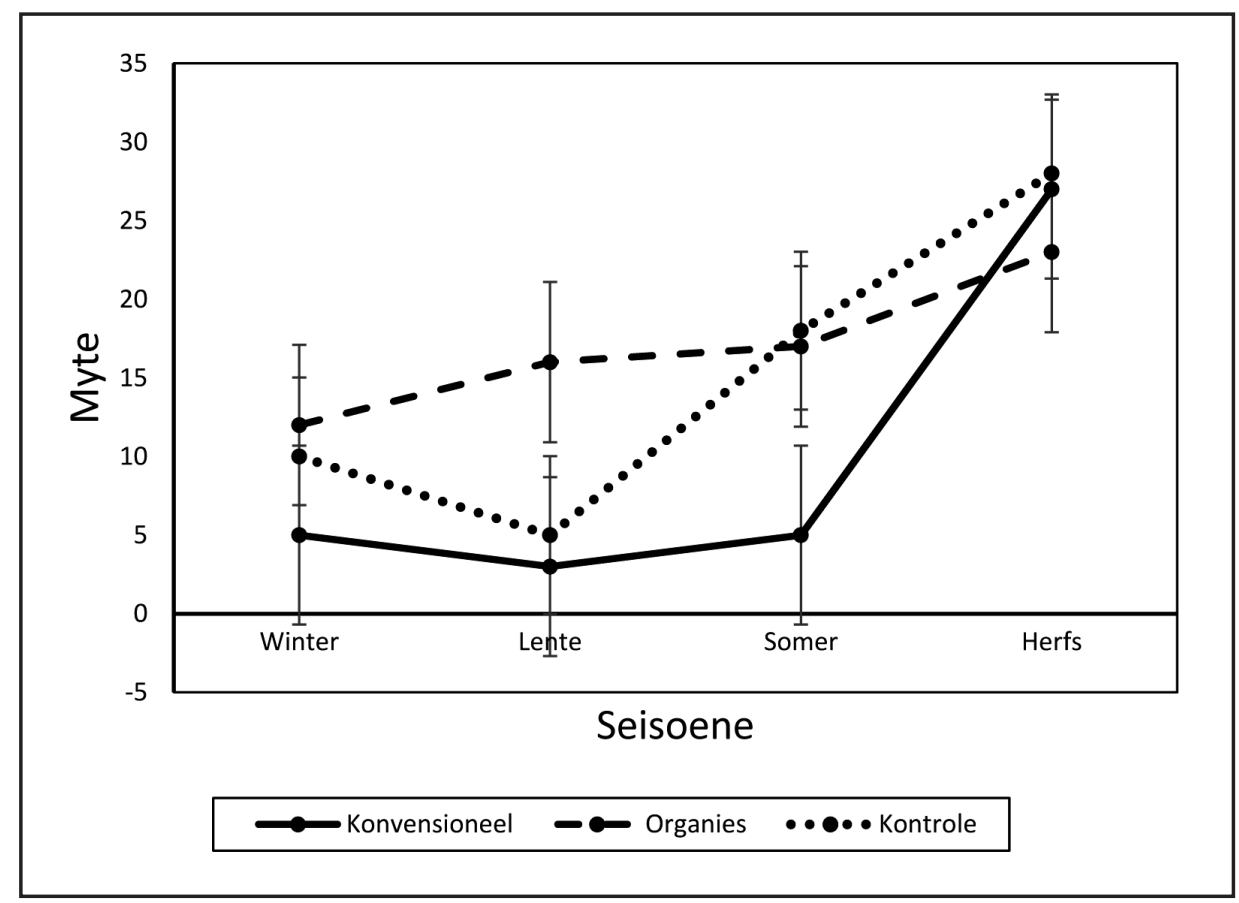

FIGUUR 3: Seisoenale getalledigtheid van myte (Acari) in die organiese, konvensionele en kontrolepersele. [behandeling*seisoen; LS Gemiddeld; Effek: $F(6.259)=2.5191, p=0.2185$. Vertikale kolomme - betroubaarheidsvlak 0.95] 
konvensionele perseel as in die kontrole en organiese persele. Volgens hierdie indeks het die diversiteit in die verskillende persele en seisoene baie varieer en het geen spesifieke perseel of bewerkingswyse se bevolking 'n dominante posisie ingeneem nie.

\section{Biologiese aktiwiteit}

\section{Voedingsaktiwiteit}

Die resultate van die aaslamina-studie word grafies as voedingsprofiel in Figuur 5 weergegee vir die drie verskillende persele. Daar was geen statisties betekenisvolle verskille tussen die verskillende voedingsdieptes per perseel vir enige van die drie behandelings nie $(p=0.9885)$. Indien die voedingsaktiwiteit as geheel tussen die verskillende behandelings egter vergelyk word, was die aktiwiteit in die kontroleperseel op die meerderheid dieptes betekenisvol laer as in die konvensionele en organiese persele wat dui op 'n laer aktiwiteit in die natuurlike kontroleperseel. Die voedingsaktiwiteit het 'n matige toename getoon vanaf Junie tot en met die laaste opnames in September. Indien die resultate van al die opnames oor die hele versamelperiode vir elke perseel afsonderlik saamgevoeg word, was die grondbiologiese aktiwiteit, soos met die aaslaminas gemeet, statisties betekenisvol hoër in die konvensionele en organiese persele

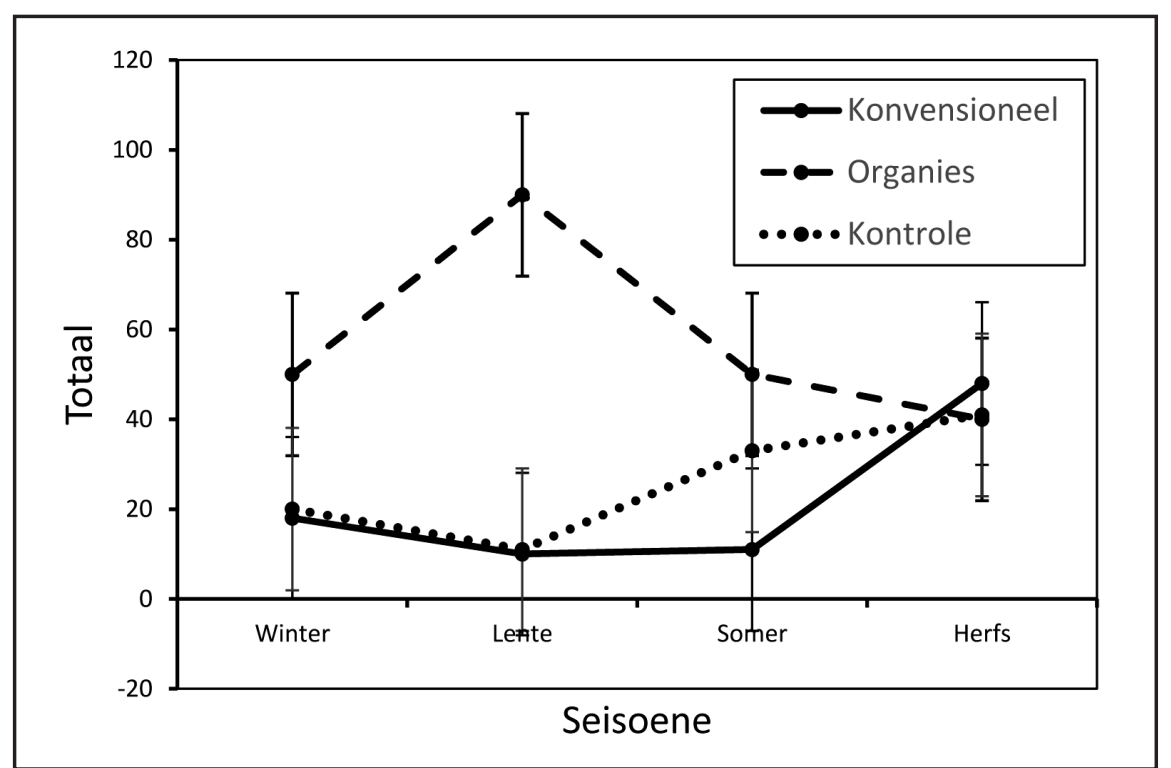

FIGUUR 4: Seisoenale tendense in die getalledigtheid van alle mesofauna in die organiese, konvensionele en kontrolepersele. [behandeling*seisoen; LS Gemiddeld; Effek: $F(6.259)=3.0344, p=0.0694$. Effektiewe hipotese ontbinding. Vertikale kolomme - betroubaarheidsvlak 0.95]

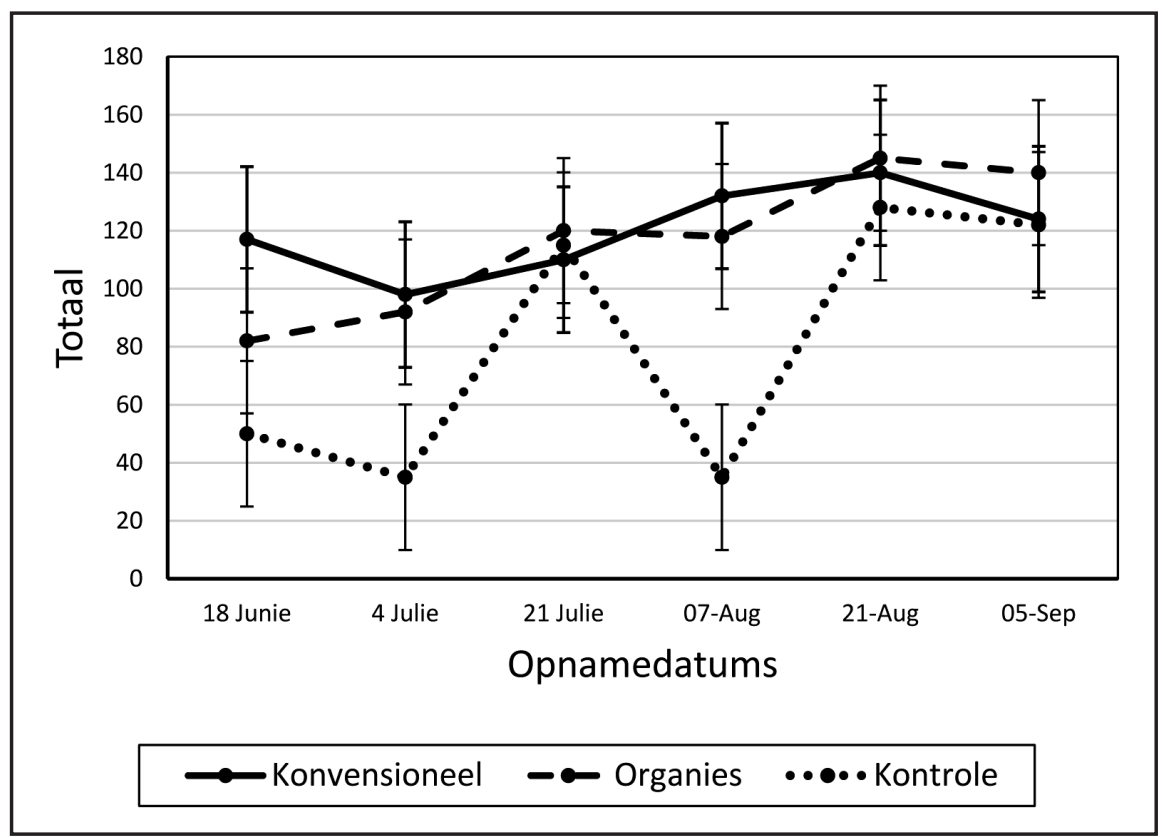

FIGUUR 5: Voedingsaktiwiteit gemeet met aaslamina op die konvensionele, organiese en kontrolepersele op die verskillende opnamedatums tussen Junie en September [datum*behandeling; LS Gemiddeld; Effek: $F(10.30)=2.6975, p=0.1730$. Vertikale kolomme - betroubaarheidsvlak 0.95] 
as in die kontroleperseel $(\mathrm{p}=0.0173)$ soos in Figuur 5 uitgebeeld. Daar was egter geen statisties betekenisvolle verskil tussen die organiese en konvensionele perseel nie.

\section{Organiese afbraak}

Die strooiselsakkies met organiese materiaal wat in die onderskeie persele begrawe is om die afbraak van organiese materiaal te meet, word in Figuur 6 voorgestel. Beide die konvensionele $(p=0.000385)$ en die organiese perseel $(p=0.000675)$ het 'n statisties betekenisvol hoër aktiwiteit getoon (soos weerspieël deur die gewigsvermindering van die sakkies se inhoud) as die kontroleperseel. Daar was 'n 30 to $40 \%$ vermindering in die gewig van die strooiselsakkies wat in hierdie twee persele begrawe was. Die sakkies wat in dieselfde periode in die kontroleperseel was, het 'n gewigsverlies van slegs 15 tot $25 \%$ getoon. Dit dui, soos ook in die geval van die aaslamina studie, daarop dat die aktiwiteit in die natuurlike, onbewerkte kontrolegrond laer was as in die twee bewerkte persele.

\section{Grondrespirasie}

Die $\mathrm{CO}_{2}$-vloed in die grond kan as maatstaf van grondrespirasie en biologiese aktiwiteit dien. Dit het 'n veel hoër waarde vir die onbewerkte kontroleperseel (0.6 en $1.2 \mathrm{mg}$ / $\mathrm{kg}$ onderskeidelik vir twee temperature) teenoor die konvensionele $(0.2$ en $0.4 \mathrm{mg} / \mathrm{kg}$ onderskeidelik vir die twee temperature) en die organiese perseel getoon.

\section{Bespreking}

Die getalle van die Collembola het redelik konstant gebly gedurende die hele opnameperiode in sowel die kontroleas die konvensionele persele. Dit kan moontlik verklaar word deur die feit dat die eudafiese en hemi-eudafiese spesies van die Collembola dwarsdeur die jaar kan voortplant indien toestande gunstig genoeg is (Lavelle \& Spain 2001). Omdat daar geen statisties betekenisvolle verskil tussen die kontrole- en die kovensionele perseel se getalle was nie, kan daaruit afgelei word dat die teenwoordigheid van verskeie plaagmiddels in die konvensionele perseel moontlik nie 'n beduidende invloed op die getalle van Collembola gehad het oor die studieperiode nie.

Petersen (2002) het in teenstelling hiermee laer digthede van die Collembola in konvensioneel bewerkte grond as in natuurlike grond gevind. Dit is in teenstelling met die resultate van die huidige studie maar kan nie direk vergelyk word nie omdat toestande en behandelings verskil het en daar ' $n$ andersoortige spesiesamestelling was.

Die seisoenale veranderinge in die getalle van die myte per perseel het, soos in die geval van die Collembola, heelwat fluktueer maar nie beduidend tussen seisoene verskil nie. Aangesien dit nie die doel was om hierdie seisoenale fluktuasies binne en tussen persele met veranderinge in omgewingsfaktore soos vog en temperatuur te korreleer

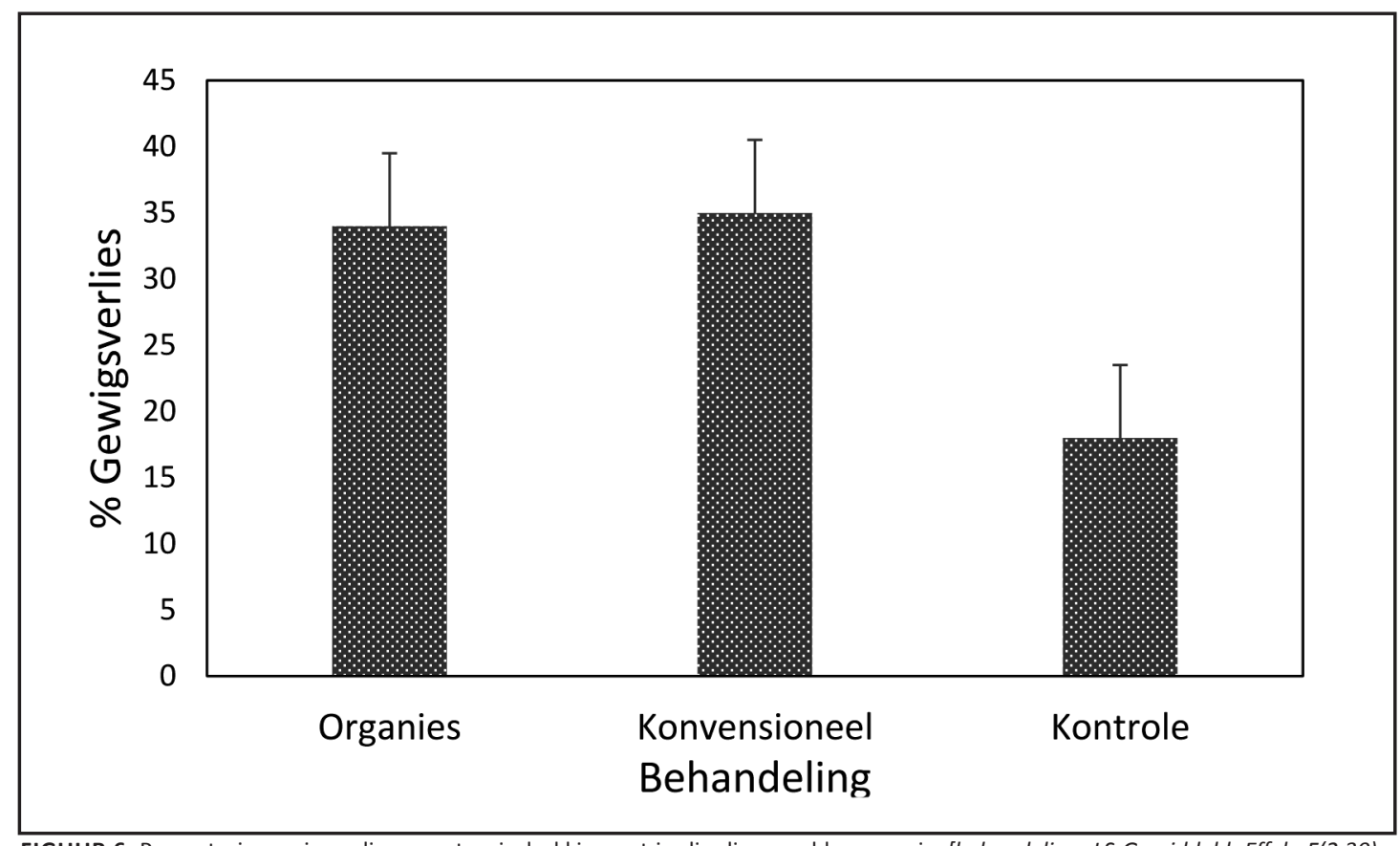

FIGUUR 6: Persentasie gewigsverlies van strooiselsakkies wat in die die grond begrawe is. [behandeling; LS Gemiddeld; Effek: F(2.30) = 12.316, $p=0.00012$. Vertikale kolomme - betroubaarheidsvlak 0.95] 
nie, en aanvaar is dat dit baie eenders sou wees vir die naasliggende persele, is moontlike verklarings vir verskille nie verder ondersoek nie. Die verskille in die bewerkinspraktyke het skynbaar geen ooglopende, onderskeidende uitwerking op die getalledigtheid van enige van die twee groepe van die mesofauna gehad nie. Hoewel plaagmiddels 'n negatiewe uitwerking op myte en springsterte kan uitoefen, is die gevolge skynbaar van korte duur en herstel die bevolkings gou weer afhangende van die tipe plaagmiddels (Larink 1997). Dit blyk ook uit die resultate van die huidige studie waar die mesofauna van die konvensionele perseel wat bespuit is, nie beduidend van die organiese perseel verskil het nie. Inteendeel, was die getalle van die mesofauna in die natuurlike kontrolegrond meestal op 'n laer vlak, wat daarop dui dat die toestande in die twee bewerkte persele die mesofauna bevoordeel het.

Die voedingsaktiwiteit in al drie persele het ' $n$ matige toename getoon vanaf Junie tot en met die laaste opnames in September. Hoewel die reënvalpatroon en verandering in grondvog nie gemeet is nie, val die opnameperiode saam met die tyd van die jaar wanneer die grondvoginhoud meer gunstig is. Indien die resultate van al die opnames oor die hele periode vir elke perseel afsonderlik saamgevoeg word, was die grondbiologiese aktiwiteit, soos met die aaslaminas gemeet, statisties betekenisvol hoër in die konvensionele en organiese persele as in die kontroleperseel ( $p=0.0173$ ). Hierdie opvallende verskil mag die resultaat wees van die feit dat die twee bewerkte persele toevoeging van organiese bemestingstowwe ontvang het wat voordelig was vir die organismes en tot verhoogde voedingsaktiwiteit in die grond gelei het. Larink en Sommer (2002) het hoë aktiwiteit van grondfauna gevind wanneer die grondvog hoog is. Trouens, Gongalsky et al, (2004) is van oordeel dat abiotiese faktore 'n belangriker rol kan speel in die aaslamina toets as die diversiteit en getalle organismes. Die gebruik van 'n strooi dekkaag en dekgewasse dra by tot behoud van voginhoud in wingerde en het skynbaar ook in hierdie geval biologiese aktiwiteit bevoordeel.

Daar was geen statisties betekenisvolle verskil tussen die totale aktiwiteit in die organiese en konvensionele perseel nie, ten spyte daarvan dat die konvensionele perseel voor en gedurende die opnameperiode met 'n verskeidenheid swamdoders bespuit is en die kontroleperseel nie (Tabel 1). Daaruit kan afgelei word dat hierdie swamdoders, soos onder andere Mancozeb, nie as besonder "aggressiewe" stowwe beskou kan word nie soos blyk uit studies met erdwurms wat aan voorgeskrewe dosisse blootgestel is (Vermeulen et al,2001). Dit mag ook wees dat die mesofauna weens die strooibedekking en dekgewasse aan lae konsentrasies van die stowwe blootgestel is. Scopel et al., (2019) het bevind dat verskeie spesies van die Collembola wel baie gevoelig is vir sekere swamdoders.

Die afbraak die organiese materiaal in die strooiselsakkies wat in die onderskeie persele begrawe is (Figuur 6), het in beide die konvensionele en die organiese perseel statisties betekenisvol hoër afbraak getoon as in die kontroleperseel. Hierdie resultaat ondersteun die bevinding wat met die aaslamina-strokies verkry is, maar ook in hierdie geval het die konvensionele en organiese persele nie betekenisvol van mekaar verskil nie. Die vraag oor die uitwerking en rol van die chemiese middels op die ontbindingsproses word dus nie deur ons gegewens beantwoord nie en daar word vermoed dat dit nie in die onderhawige geval 'n noemenswaardige rol gespeel het nie. Aangesien die dosisse en spuitfrekwensie nie bekend is nie en ons geen totale beeld van die bevolkingsgetalle en verskeidenheid van die mikro-organimes en mesofauna en -flora het nie, kan afleidings nie gemaak word om die verskynsel bevredigend te verklaar nie. Volgens bevindings van Paulus et al. (1999) het landboustowwe ook geen invloed gehad op die ontbindingskoers van strooisel tydens hulle studie nie.

Die $\mathrm{CO}_{2}$-vloed in die grond word as maatstaf van grondrespirasie en biologiese aktiwiteit beskou maar in hierdie studie het dit 'n resultaat opgelewer wat heeltemal teenstrydig is met die bevindinge met die aaslamina en die strooiselsakkies. Die hoogste respirasiekoers is in die onbewerkte kontroleperseel gemeet. Dit sou kon beteken dat die biologiese aktiwiteit in hierdie perseel nie bevredigend deur die aaslamina en strooiselsakkies gemeet is nie en nie as betroubare maatstaf van die totale biologiese aktiwiteit kan dien nie omdat dit net 'n gedeelte daarvan meet.

Die produksie van $\mathrm{CO}_{2}$ by die grondoppervlak is die resultaat van verskeie respirasieprosesse wat deur verskillende omgewingsfaktore beinvloed word. Bykans die helfte van die produksie is afkomstig van metaboliese aktiwiteit vir die groei van wortels en gepaardgaande mikorissas (Hanson et al., 2000; Hőgberg et al., 2001). Die res is hoofsaaklik heterotrofe respirasie vanaf mikrobiese gemeenskappe (Trumbore 2006) en dit is onseker watter deel daarvan aan die mesofauna toegeskryf kan word en watter deel aan die mikrobiese aktiwiteit (Hartmann et al., 2015). 'n Eenmalige meting by twee temperature is nie voldoende om 'n verteenwoordigende beeld te verkry van die verandering wat van tyd tot tyd mag intree nie. Om hierdie redes behoort die metings nie direk vergelyk te word met die metings van voedingsaktiwiteit en afbraak wat oor verskeie maande verkry is nie.

Dit is nie bekend watter effek die spuit van verskillende swamdoders op die respirasie van die mikrobiese gemeenskappe in die twee bewerkte persele gehad het nie. Reinecke et al. (2002) en Edwards \& Stafford (1979) het selfs bevind dat sekere onkruiddoders 'n voordelige uitwerking op biologiese aktiwiteit in die grond kan uitoefen. Volgens Hopkin (1997) is die mikrobes en die meso- en makrofauna verantwoordelik vir die omset van organiese koolstof na $\mathrm{CO}_{2}$ en dat die Collembola slegs tussen 1 en $5 \%$ in gematigde gebiede tot respirasie bydra terwyl die mikro-organismes 'n belangriker rol speel (Wang et al. 2003). 


\section{Gevolgtrekking}

Geen beduidende verskil in getalledigtheid, diversiteit en aktiwiteit van die mesofauna is tussen die organies- en die konvensioneelbewerkte grond gevind nie. Dus kan ons gestelde hipotese nie aanvaar word dat die konvensionele praktyk, soos hier be-oefen, nadeliger was as die organiese bewerking nie. Wat die aktiwiteit van die mesofauna betref, was daar egter beduidend hoër aktiwiteit in die twee bewerkte persele as in die onbewerkte, natuurlike kontroleperseel. Die toestande in die twee bewerkte persele wat deur grondbreking, dekgewasverbouing, organiese bemesting en strooibedekking geskep is, was onder heersende omgewingstoestande dus gunstiger. Geen nadelige effek van die chemiese bespuiting op die mesofauna is aangetoon nie. Meer verfynde metings oor langer termyne is steeds nodig om die uitwerking van diverse chemiese bespuitingspraktyke te ondersoek.

\section{Bedankings}

Ons bedank graag by die Universiteit van Stellenbosch die personeel van die statistiese konsultasiediens vir statistiese ontledingss; lede van die Departement Grondkunde vir grondontledings en $W$. Nel vir veldopnames en ekstraksies. Die studie is moontlik gemaak deur die finansiële steun van die Nasionale navorsingstigting (NRF) en die Universiteit van Stellenbosch.

\section{Outeurs se bydrae}

AJR was verantwoordelik vir die konsepsuele ontwerp van die studie en die skryf van die artikel. Albei outeurs was betrokke by die literatuurstudie, die insameling van gegewens en die interpretasie daarvan. SAR was verantwoordelik vir die finale redigering.

\section{Literatuurverwysings}

Briones, M.J.I. 2014. Soil fauna and soil functions: a jigsaw puzzle. Frontiers in Environmental Science 2, 2-7. https://doi.org/10.3389/fenvs.2014.00007.

Brussaard, L. 1998. Soil fauna, guilds, functional groups and ecosystem processes. Applied Soil Ecology 9, 123-135. https://doi.org/10.1016/S0929processes. Applied

Burrows, L.A., Edwards, C.A. 2002. The use of integrated soil microcosms to predict effects of pesticides on soil ecosystems. European Journal of Soil Biology 38 315-319. https://doi.org/10.1016/S1164-5563(02)01153-6.

Bocock, K.L. Gilbert, O.J.W. 1957. The disappearance of leaf litter under different woodland conditions. Plant and Soil 9, 179-185. https://doi.org/10.1007/ BF01398924.

Cancela da Fonseca, J.P., Sarkar, S. 1996. On the evaluation of spatial diversity of soil microarthropod communities. European Journal of Soil Biology 32, 131-140.

Cortet, J., Poinsot-Balaguer, N., Beaufreton, C., et al. 2002. Impacts of different agricultural practices on the biodiversity of microarthropod communities in agricultural practices on the biodiversity of microarthropod communities in
arable crop systems. European Journal of Soil Biology 38, 239-244. https://doi. org/10.1016/S1164-5563(02)01152-4.

Edwards, C.A., Stafford, C.J. 1979. Interactions between herbicides and soil fauna. Proceedings of the Association of Applied Biology 91, 132-137.

Eisenbeis, G., Wichard, W. 1987. Atlas on the biology of soil arthropods. SpringerVerlag, Berlin. https://doi.org/10.1007/978-3-642-72634-7.

Flores, S.S. 2018. What is sustainability in the wine world? A cross-country analysis of wine sustainability frameworks. Journal of cleaner production, 172, 2301 2312. https://doi.org/10.1016/j.jclepro.2017.11.181.

Gaigher, R., Samways, M.J. 2010. Surface-active arthropods in organic vineyards, integrated vineyards and natural habitat in the Cape Floristic Region. Journal of Insect Conservation, 14, 595-605. https://doi.org/10.1007/s10841-0109286-2.

Giller, K.E., Witter, E., Corbeels, M., Tittonell, P. 2009. Conservation agriculture and smallholder farming in Africa: the heretics' view. Field crops research 114, 23 34. https://doi.org/10.1016/j.fcr.2009.06.017.

Gomeiro, T., Pimentel, D., Paoletti, M.G. 2011. Environmental impact of different agricultural management practices: conventional vs. organic agriculture. Critical reviews in plant sciences 30, 95-124. https://doi.org/10.1080/07352 689.2011.554355.

Gongalsky, K.B., Pokarzhevskii, A.D., Filimonova, Z.V., Savin, F.A. 2004. Stratification and dynamics of bait-lamina perforation in three forest soils along a northand dynamics of bait-lamina perforation in three forest soils along a north-
south gradient in Russia. Applied Soil Ecology 25, 111-122. https://doi. south gradient in Russia. Applied
org/10.1016/j.apsoil.2003.09.001.

Hanson, P.J., Edwards, N.T., Garten, C.T., Andrews, J.A. 2000. Separating root and soil microbial contributions to soil respiration: a review of methods and observations. Biogeochemistry 48, 115-146. https://doi. org/10.1023/A:1006244819642.

Hartmann, M., Frey, B., Mayer, J., Mäder, P., Widmer, F. 2015. Distinct soil microbial diversity under long-term organic and conventional farming. The ISME journal 9, 1177-1194. https://doi.org/10.1038/ismej.2014.210.

Helling, B., Pfeiff, G., Larink, O. 1998. A comparison of feeding activity of collembolan and enchytraeid in laboratory studies using the bait-lamina test. Applied Soi Ecology 7, 207-212. https://doi.org/10.1016/S0929-1393(97)00065-6.

Henneron, L., Bernard, L., Hedde, M., et al. 2015. Fourteen years of evidence for positive effects of conservation agriculture and organic farming on soil life Agronomy for Sustainable Development 35, 169-181. https://doi.org/10.1007/ s13593-014-0215-8.

Hőgberg, P., Nordgren, A., Buchmann, N., et al. 2001. Large-scale forest girdling shows that current photosynthesis drives soil respiration. Nature 411, 789792. https://doi.org/10.1038/35081058.

Hole, D.G., Perkins, A.J., Wilson, J.D., et al. 2005. Does organic farming benefit biodiversity? Biological conservation 122, 113-130. https://doi.org/10.1016/j. biocon.2004.07.018.

Hopkin, S.P. 1997. Biology of Springtails, Insecta: Collembola. Oxford University Press, Oxford

Kratz, W. 1998. The bait-lamina test. General aspects, applications and perspectives. Enviromental Science and Pollution 5, 94-96. https://doi.org/10.1007/ BF02986394.

Larink, O. 1994. Bait lamina as a tool for testing feeding activity of animals in contaminated soils, in: Donker, M.H., Eisjackers, H., Heimbach, F., (Reds.), Ecotoxicology of soil organisms, Lewis Publisher, Boca Raton, Ann Arbor, London, pp. 339-345.

Larink, O. 1997. Springtails and Mites: Important Knots in the Food Web of Soils, in: Benckiser, G. (Red.), Fauna in Soil Ecosystems: Recycling Processes, Nutrient Fluxes, and Agricultural Production, Marcel Dekker, Inc., New York, pp. 225264.

Larink, O., Sommer, R. 2002. Influence of coated seeds on soil organisms tested with bait lamina. European Journal of Soil Biology 38, 287-290. https://doi. org/10.1016/S1164-5563(02)01161-5.

Lavelle, P., Spain, A.V. 2001. Soil Ecology. Kluwer Academic Publishers, London.

Macfadyen, A. 1961. Improved funnel type extractors for soil arthropods. Journal of Animal Ecology 30, 171-184. https://doi.org/10.2307/2120.

Mateo, M. A., Romero, J. 1996. Evaluating seagrass leaf litter decomposition: an experimental comparison between litter-bag and oxygen-uptake methods. Journal of Experimental Marine Biology and Ecology 202, 97-106. https://doi. org/10.1016/0022-0981(96)00019-6.

Mayer, J., Gunst, L., Mäder, P., Samson, et al. 2015. Productivity, quality and sustainability of winter wheat under long-term conventional and organic
management in Switzerland. European Journal of Agronomy 65, 27-39. management in Switzerland. European
$\mathrm{https} / / /$ doi.org/10.1016/j.eja.2015.01.002.

Mills, A.J., Fey, M.V. 2004. Frequent fires intensify soil crusting: physiochemical feedback in the pedoderm of long-term burn experiments in South Africa. Geoderma 121, 45-64. https://doi.org/10.1016/j.geoderma.2003.10.004.

Paulus, R., Römbke, J., Ruf, A., Beck, L. 1999. A comparison of the litterbagminicontainer- and bait-lamina- methods in an ecotoxicological field experiment with diflubenzuron and btk. Pedobiologia 43, 120-133.

Petersen, H. 2002. General aspects of collembolan ecology at the turn of the millennium. Pedobiologia 46, 246-260. https://doi.org/10.1078/0031-405600131.

Picker, M., Griffiths, C., Weaving, A. 2002. Field Guide to Insects of South Africa. Struik Publishers, Cape Town.

Reardon, M., Forbes, A.A. 2001. Abundance and recruitment of soil invertebrates to different plant litter types in an fertigated oak plot and an control oak plot at the Falmouth sewage treatment plant. Course notes, Gettysburg College, VA, USA. 
Reinecke, A.J., Helling, B., Louw, K., Fourie, J., Reinecke, S.A. 2002. The impact of different herbicides and cover crops on soil biological activity in vineyards in the Western Cape, South Africa. Pedobiologia 46, 475-484. https://doi. org/10.1078/0031-4056-00153.

Reinecke, A.J., Albertus, R.M.C., Reinecke, S.A., Larink, O. 2008. The effects of organic and conventional management practices on feeding activity of soil organisms in vineyards. African Zoology, 43, 66-74. https://doi.org/10.3377/15627020(2008)43[66:TEOOAC]2.0.CO;2.

Reinecke, S.A., Reinecke, A.J. 2007. The impact of organophosphate pesticides in orchards on earthworms in the Western Cape, South Africa. Ecotoxicology
and Environmental Safety, 66, 244-251. https://doi.org/10.1016/j. and Environmental

Reinecke, A.J., Reinecke, S.A. 2018. Is soil biodiversity threatened by anthropogenic environmental changes? South African Journal of Science and Technology, 37, 1-11.

Trumbore, S. 2006. Carbon respired by terrestrial ecosystems-recent progress and challenges. Global Change Biology, 12, 141-153. https://doi.org/10.1111/ j.1365-2486.2006.01067.x.
Tuck, S.L., Winqvist, C., Mota, F., et al. 2014. Land-use intensity and the effects of organic farming on biodiversity: a hierarchical meta-analysis. Journal of applied ecology, 51, 746-755. https://doi.org/10.1111/1365-2664.12219.

Van Straalen, N.M., Rijninks, P.C. 1982. The efficiency of Tullgren apparatus with respect to interpreting seasonal changes in age structure of soil arthropod populations. Pedobiologia, 24, 197-209.

Vermeulen, L.A., Reinecke, A.J., Reinecke, S.A. 2001. Evaluation of the fungicide manganese-zinc ethylene bis (dithiocarbamate) (Mancozeb) for sublethal and acute toxicity to Eisenia fetida (Oligochaeta). Ecotoxicology and Environmental Safety, 48, 183-189. https://doi.org/10.1006/eesa.2000.2008.

Von Törne, E. 1990. Assessing feeding activities of soil-living animals: I. Bait-lamina tests. Pedobiologia, 34, 89-101.

Wang, W.J., Dalal, R.C., Moody, P.W., Smith, C.J. 2003. Relationships of soil respiration to microbial biomass, substrate availability and clay content. Soil Biology and Biochemistry, 35, 273-284. https://doi.org/10.1016/S00380717(02)00274-2. 